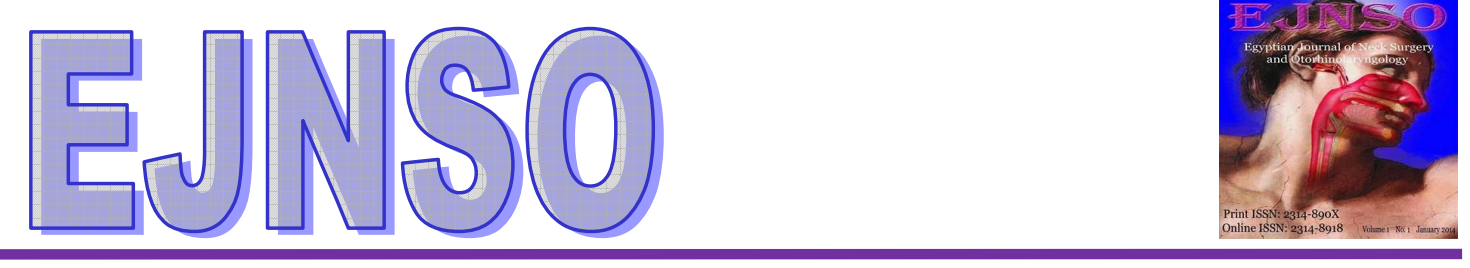

\title{
A novel Approach to Sphenoid Sinus Using Maxillary Sinus as a Landmark.
}

\author{
Ibrahim Rezk ${ }^{\mathrm{a}}$ and Waleed A.M. Abdelhameed ${ }^{\mathrm{b}}$ \\ a- Lecturer of E.N.T. Otorhinolaryngology Department, Sohag Faculty of Medicine, Sohag University. \\ b- Associate Professor of E.N.T. Otorhinolaryngology Department, Sohag Faculty of Medicine, Sohag University.
}

Received: $26 / 1 / 2014$

Revised: 7/2/2014

Accepted: 1/4/2014

Keywords:

sphenoid face , middle meatal antrostomy, revision endoscopic sinus surgery.

\begin{abstract}
:
Introduction: The location of the natural ostium of the sphenoid sinus in the surgical field has been variably reported according to different standard points. However because of the more severe pathological changes, massive polyps in nasal cavities and altered anatomic reference points, revision endoscopic sinus surgery often challenges surgeon`s skill and experience. Through endoscopic sinus surgeries in our department, we noticed a constant relationship between middle meatal antrostomy and site of sphenoid face.

Objectives: To establish a novel approach to sphenoid sinus using middle meatal antrostomy as a landmark in difficult cases of endoscopic sinus surgery with lost landmarks or revision ones.

Study design: A prospective study

Patients and methods: Fifteen patients (6 males, 9 females), with mean age of 37.7 years, have been operated with endoscopic sinus surgery for different pathologies. After finishing middle meatal antrostomy and sphenoidotomy, we drew an imaginary line between point at most posteroinferior margin of antrostomy (flush with posterior wall of maxillary sinus), directed superiomedially to posterior part of septum and touching superior limit of sphenoid face.

Results: On the images recorded after operation, we measured the angle between this line and the horizontal; it ranged between $40-45^{\circ}$, with a mean of $41.5^{\circ}$. This line had a mean length of $17.1 \mathrm{~mm}$. The anterior wall of sphenoid was always below this line.

Conclusion: A reference point on middle meatal antrostomy can be used as constant landmark to identify face of sphenoid sinus. This is mostly helpful in difficult cases of endoscopic sinus surgery.
\end{abstract}

\section{1-Introduction:}

Approaches to the sphenoid sinus include both open and endoscopic techniques.

The endoscopic approach can proceed in transethmoid fashion or directly through anterior sphenoid sinus wall at the site of the natural ostium ${ }^{1}$.

The location of the natural ostium of the sphenoid sinus in the surgical field has been variably reported according to different standard points ${ }^{2}$.

First, it is known to be located 10$20 \mathrm{~mm}$ superiorly from the base of the sphenoid sinus and $3 \mathrm{~mm}$ medially and 5 $\mathrm{mm}$ superiorly from the posterior end of the inferior turbinate ${ }^{3}$.

It is also known to be located 10-12 $\mathrm{mm}$ superiorly from the top of the choana $^{4}$. 
According to Levin and May, it is much easier to find the sphenoid sinus when using the posteroinferior end of middle turbinate as a standard point ${ }^{5}$.

Because of the more severe pathological changes, massive polyps in the nasal cavities, hyperostotic ethmoid cells, and altered anatomic reference points, Revision Endoscopic Sinus Surgery (RESS) often challenges surgeon`s skills and experience ${ }^{6}$.

Anatomic disorientation during Endoscopic Sinus Surgery (ESS) may result in significant intraoperative and postoperative complications. The risk becomes even greater in patients with obscured anatomic landmarks secondary to prior surgery ${ }^{7,8}$.

During work on ESS, we noticed a constant relationship between Middle Meatal Antrostomy (MMA), face of sphenoid, and posterior ethmoidal air cells. This study was designed to establish an approach to sphenoid sinus using MMA as a landmark. This would be helpful in difficult cases of endoscopic sinus surgery with lost landmarks or revision ones.

\section{2- Patients and Methods:}

Our study included fifteen patients (6 males and 9 females), who had been operated with ESS for different pathologies.

Their age ranged between 23-60 years with a mean of $37.7 y s$. We only obtained

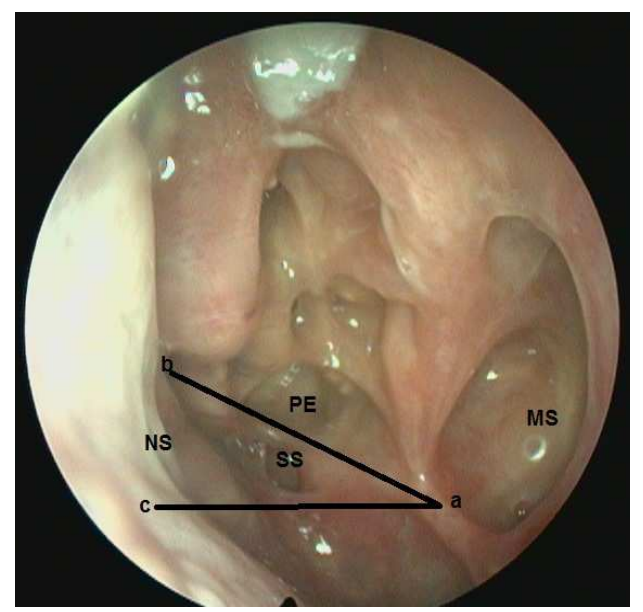

Fig.1: Postoperative endoscopic view, showing studied line (ab) extending between point at most postero inferior end of MMA and posterior part of nasal septum (NS).(ac) line represents horizontal plane, (SS) sphenoid sinus is below this line, (PE) posterior ethmoid cells are above it, (MS) maxillary sinus. their consent for surgical procedure, as our work did not interfere with their treatment. During ESS and after finishing MMA, we found that we could follow an imaginary line from posterior end of MMA to site of sphenoid ostium.

After completing the procedure, we recorded images including MMA, sphenoidotomy, opened posterior ethmoid cells. This was done by using R.Wolf $30^{\circ}$ lens connected to Storz Telepack $\mathrm{X}$ camera. Paint Program of Windows 7 Software was used on recorded images to draw a line between point at most posteroinferior end of MMA (To be flush with posterior wall of maxillary sinus) directed superiorly and medially to posterior part of the nasal septum, touching the superior limit of sphenoid face and separating the sphenoidotomy below from posterior ethmoid cells above and lateral, as shown in Figure 1.

\section{3- Results:}

The angle between this line (We could call it: Rezk-Abdelhameed line) and Horizontal plane was measured and found to range from $40-45^{\circ}$ with a mean of $41.5^{\circ}$ \pm 1.9 , Figure 2.shows the recorded angles for patients, this line has a length ranging from $16.5-18 \mathrm{~mm}$, with a mean of $17.1 \pm 0.9 \mathrm{~mm}$.

Anterior wall of sphenoid is always identified just below this line, and posterior ethmoid cells above and lateral.

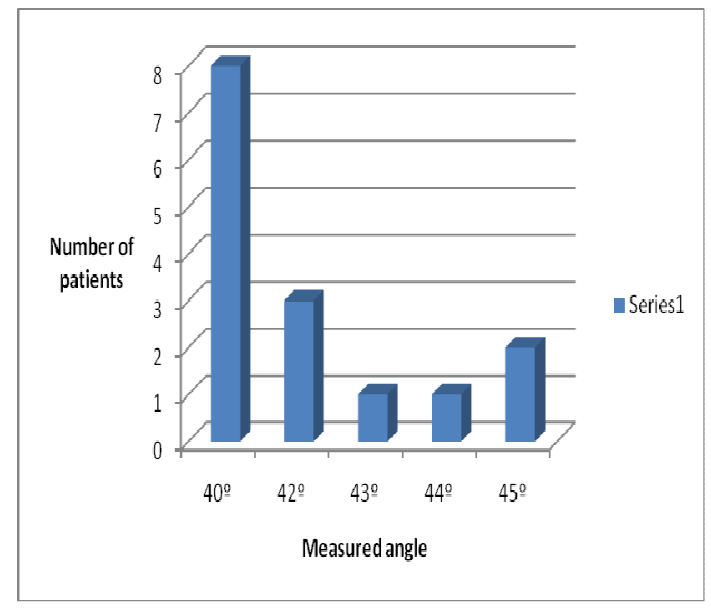

Fig.2: Degree of angle between line extending from MMA to sphenoid face and horizontal. 
Table.1: Patients' presentations and type of performed operations.

\begin{tabular}{|c|c|c|}
\hline Type of Pathology & Patients & Operations \\
\hline Recurrent bilateral nasal polypi & $\begin{array}{l}5 \text { Females. } \\
(35,48,25,30,43 \text { ys })\end{array}$ & \multirow{5}{*}{$\begin{array}{l}\text { Bilateral Middle Meatal } \\
\text { Antrostomy (MMA), } \\
\text { Bilateral anterior and } \\
\text { posterior ethmoidectomy, } \\
\text { Bilateral sphenoidotomy. } \\
\pm \text { Bil.frontal sinustomy (5 } \\
\text { cases). } \\
\pm \text { Septoplasty } \\
\text { ( } 3 \text { cases). }\end{array}$} \\
\hline Bilateral nasal polypi. & $\begin{array}{l}3 \text { Females }(26,30,40 \text { ys }) \\
1 \text { Male ( } 45 \text { ys }) .\end{array}$ & \\
\hline $\begin{array}{l}\text { Recurrent bilateral allergic } \\
\text { fungal sinusitis. }\end{array}$ & $\begin{array}{l}1 \text { Female }(40 \text { ys }) \\
1 \text { Male ( } 32 \text { ys })\end{array}$ & \\
\hline Bilateral allergic fungal sinusitis & 1 Male (39 ys) & \\
\hline $\begin{array}{l}\text { Recurrent bilateral inverted } \\
\text { papilloma }\end{array}$ & 1 Male ( 60 ys) & \\
\hline $\begin{array}{l}\text { Recurrent unilateral allergic } \\
\text { fungal sinusitis }\end{array}$ & 1 Male (48 ys) & \multirow{2}{*}{$\begin{array}{l}\text { Unilateral MMA, anterior and } \\
\text { posterior ethmoidectomy, } \\
\text { sphenoidotomy, frontal } \\
\text { sinustomy. }\end{array}$} \\
\hline $\begin{array}{l}\text { Recurrent unilateral inverted } \\
\text { papilloma }\end{array}$ & 1 Male (40 ys) & \\
\hline
\end{tabular}

\section{4- Discussion:}

The task of finding the natural ostium of the sphenoid is often difficult, even for most experienced surgeons. Despite this, little anatomical research has been undertaken concerning the location of the natural ostium of the sphenoid sinus ${ }^{9}$.

There are different standard points to locate the natural ostium. According to Kim et al. 2001, the position of the natural ostium was approximately $1 \mathrm{~cm}$ above the posteroinferior end of superior turbinate, which corresponds to middle region of anterior wall of sphenoid face ${ }^{2}$. It is also known to be located $10-12 \mathrm{~mm}$ superiorly from the top of choana ${ }^{4}$.

Hidir et al, 2011, measured the optimum height that the sphenoid sinus ostium can be probed safely from the roof of choana in 100 patients, using their CT scans, and found that distance between $13.3 \mathrm{~mm}$ (the minimum skull base height) and $5.7 \mathrm{~mm}$ (The minimum sphenoid ostium height $)^{10}$.

In another study, using CT scans, Lee et al, considered medial maxillary sinus roof as a reference point, the mean vertical distance to natural sphenoid sinus ostium, sphenoid roof and sphenoid floor was $2.76,12.18$, and $5.94 \mathrm{~mm}^{\text {respectively }}{ }^{11}$.

The current study was built on observation of the relation between MMA and sphenoid sinus ostium, and was translated to a stable landmark connecting most posteroinferior end of MMA and superior limit of sphenoid sinus. It had the advantage of being done on livings with more practical applications to surgeons going to do sphenoidotomy.

This proposed (Rizk-Abdelhameed) line, can be used in further research to define actual site of natural ostium of sphenoid.

Limitations: This work still needs radiological support. This was not feasible in the current study as there was no strong indication to repeat CT scan after a successful surgery.

\section{Conclusions:}

A reference point on MMA can be used as constant landmark to identify face of sphenoid sinus. This is mostly helpful in difficult cases of ESS, when other anatomical landmarks are lost by revision surgery or massive pathologies.

\section{References:}

1. Kieff D. and Busaba N: Treatment of isolated sphenoid sinus inflammatory disease by endoscopic sphenoidotomy 
without ethmoidectomy. Laryngoscope 2002; 112:2186-2188.

2. Kim HU, Kim SS, Kang SS, etal:Surgical anatomy of the natural ostium of the sphenoid sinus. Laryngoscope 2001;111: 1599-1602.

3. Elwany S, Yacout YM, Talaat M, etal: Surgical anatomy of the sphenoid sinus. J Laryngol Otol 1983;97: 227-241.

4. Wigand ME: Endoscopic Surgery of the Paranasal Sinuses and Anterior Skull Base. New York: Thieme Medical, 1990:53-56.

5. Levin HL, May M :Endoscopic Sinus Surgery. New York: Theme Medical, 1993: 142-144.

6. Ye J, Yu H, Draf W, Zheng C, and Wang D: Technique and results of the Anterior-to-Posterior-to-Anterior approach in revision endoscopic sinus surgery. ORL 2009; 71:257-262.

7. Ulualp S: Complications of endoscopic sinus surgery, appropriate management of complications. Curr Opin Otolaryngol Head Neck Surg 2008;16:252-259.

8. Soyka M, Holzmann D: Correlation of complications during endoscopic sinus surgery with surgeon skill level and extent of surgery. Am J Rhinol 2005; 19:274-281.

9. Davis WE, Templer J, Parsons DS: Anatomy of the paranasal sinuses. Otolaryngol Clin North Am 1996;29:57-74.

10. Hidir Y, Battal B, Durmaz A, Karaman B, Tosun F: Optimum height from the roof of the choana for seeking the sphenoid sinus ostium. J Craniofac Surg 2011; 22(3): 1077-1079.

11. Lee J, Woods T, Grewal A : Preoperative evaluation of the maxillary sinus roof as a guide for posterior ethmoid and sphenoid sinus surgery. $\mathbf{J}$ Otolaryn H N Surg. 2012; 41(5): 361369. 